\title{
Benzyl Cation Formation from the Reaction of Benzyl Alcohol with Thianthrene Cation Radical
}

\author{
Hyung Min Moon and Wang Keun Lee \\ Department of Chemistry Edtcation, Chonnam Kational Lniversity, Gitang-Ju 500-757, Korea \\ E-mail: whee ăchonnam ack' \\ Received December 26, 2008, Accepted Jantury 28, 2009
}

Key Wonds: Benzyl cation, Benzylacetamide. Thianthrene cation radical

Mechanistic studies have been reported for the reactions of thianthrene cation radical $\left(\mathrm{Th}^{+-} \mathrm{ClO}_{4}^{-}\right)$with nucleophiles such as water and alcohol. The simple reaction of $\mathrm{Th}^{+\cdot}$ with water ${ }^{1}$ generated equal amounts of thianthrene (Th) and its 5-oxide (ThO) (eq 1). The analogous study of reactions of $\mathrm{Th}^{--}$with

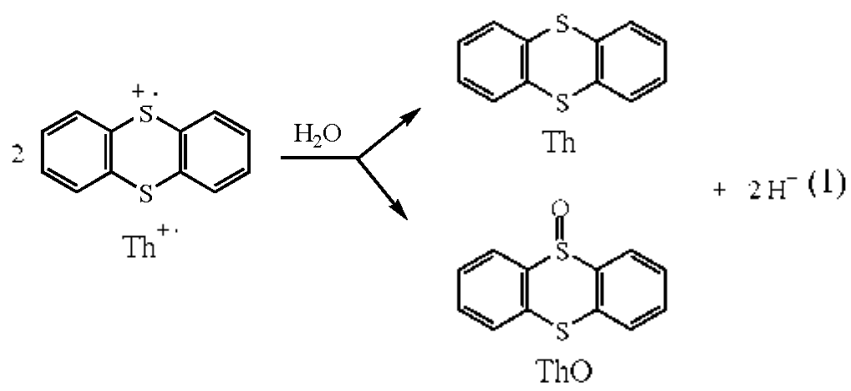

alcohols have reported by Yueh and Shine. ${ }^{-3.3}$ In their study of the reaction of $\mathrm{Th}^{--}$with benzyl alcohol (1), dibenzyl ether $(100 \%)$. Th $(52 \%)$, and ThO $(48 \%)$ were obtained as products. The stoichiometry of the reaction was a molar ratio of 1.88-2.50: 1.00 of $\mathrm{Th}^{+\cdot}$ to 1 , with the major products are not characteristic of benzyl cations but rather dibenzyl ether and without the formation of $\mathrm{N}$-benzylacetamide. With the exception of 1 . all of the substituted benzyl alcohols $\left(\mathrm{X}^{-} \mathrm{C}_{6} \mathrm{H}_{5-}\right.$ $\mathrm{CH}_{2} \mathrm{OH} . \mathrm{X}=$ methyl, halogen) gave mistures of the corresponding dibenzyl ether and $\mathrm{N}$-benzylacetamide. Yueh and Shine suggested that dibenzyl ether was formed in an $\mathrm{S}_{\mathrm{N}} 2$ displacement of ThO whereas the amides were formed by S:I loss of ThO from the ROTh ${ }^{+}$. Since our recent works ${ }^{4.5}$ have cast doubt on formation of dibenzyl ether from 1 by $\mathrm{Th}^{+-}$, the reaction of 1 with Th $^{-}$was reinvestigated in order to clarify the mechanism. We report here our new reaction mechanism proposed on the basis of our experimental results for the particular case of 1 and $\mathrm{Th}^{+}$. Reactions were carried out at a 2:1 stoichiometry of the $\mathrm{Th}^{+*}: 1$. in acetonitrile at room temperature. The products obtained were $\mathrm{N}$-Benzy lacetamide (3). Th, and ThO. as determined by quantitative GC and $\mathrm{GC} / \mathrm{MS}$ analyses. $\mathrm{N}$-Benzylacetamide (3) from the benzyl cation, isolated in a yield of $90 \%$, Th $(100 \%)$ and ThO $(90 \%)$ were formed quantitatively, according to the results of the formation of an alkoxysulfonium ion in eq $2(R=$ benzyl). Contrary to Yueh and Shine's report. in our reaction, no trace amounts of dibenzyl ether was obtained

$$
2 \mathrm{Th}^{+-}+\mathrm{R} \cdot \mathrm{OH} \rightarrow \mathrm{Th}+\mathrm{ROTh}^{+}+\mathrm{H}^{-}
$$

As expected from the stoichiometry of eq 3 . there are equivalent amounts of Th, ThO and 3 .

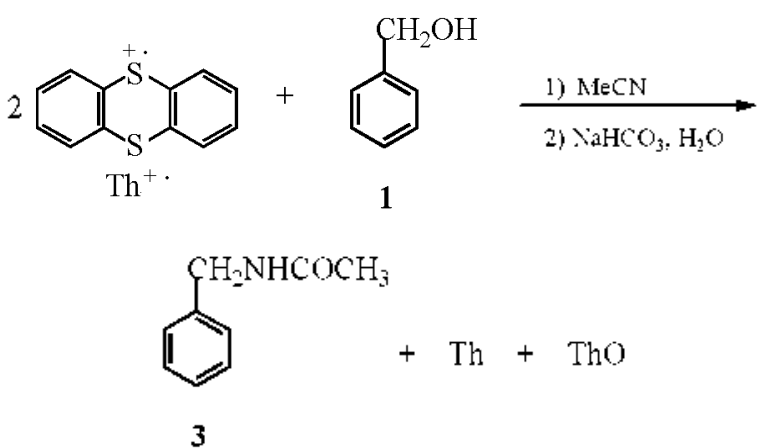

It is evident that $\mathrm{Th}^{--}$cannot oxidize 1 because of the lower oxidation potentials of $T h\left(\sim 1.3 \mathrm{~V}\right.$ vs $\left.\mathrm{SCE}^{6}\right)$ relative to alcohols $(>2 \mathrm{~V})$. Alternatively, analogous to the anisylation of $\mathrm{Th}^{+\cdot 8}$. complexation of an 1 with $\mathrm{Th}^{+}$must occur. and leads ultimately to an unstable alkoxysulfonium ion from which benzyl cation is derived by $\mathrm{S}: 1$ loss of ThO from the ROTh${ }^{+}$(eq 2), whereby the oxygen atom of 1 was transferred to $\mathrm{Th}^{+*}$ with quantitative formation of $\mathrm{ThO}$ and 3 .

In general. ThO is obtained as a side product from the hydrolysis of $\mathrm{Th}^{+-}$by water, either adventitiously in the solvent or added during work-up of the reaction of $\mathrm{Th}^{+\cdot}$ ? However. in this study, the ThO is a primary product rather than a side product. The formation of ThO as a primary product of oxy'gen transfer from nucleophiles, has been reported widely from the reaction of $\mathrm{Th}^{+-}$with nitrite and nitrate ions. oximes. ${ }^{16}$ cyclic alcohols. ${ }^{2}$ 2.3-dimethyl-2.3-butandiol. ${ }^{11}$ and azodioxide. ${ }^{12}$ Without doubt, 3 arose from hydration during work-up, from a Ritter-type intermediate $\left(\mathrm{C}_{6} \mathrm{H}_{3} \mathrm{CH}_{2} \mathrm{~N}={ }^{-} \mathrm{CMe}\right)$, from the reaction of $\mathrm{C}_{6} \mathrm{H}_{5} \mathrm{CH}_{2}{ }^{+}$with $\mathrm{MeCN}$ solvent. The chenical characteristics of the $t$-butyl cation from the cation radical-induced oxidative decomposition of nucleophiles ${ }^{12-18}$ has been documented extensively. but that of the benzyl cation known to be less stable than the $t$-butyl cation, affords very few examples of Ritter-type product. 3.

A mechauism that fits the formation of such products involves the initial complexation of $\mathrm{Th}^{+*}$ with $\mathbf{1}(\mathrm{eq} 4)$ to produce a species more easily oxidized than $\mathrm{Th}^{+\cdot}$, where electron transfer (eq 5) produces a thianthrene dication-benzyl alcohol complex $(\text { Th-1 })^{--}$that undergoes a rate-deternining bond formation with expulsion of a proton (eq 6 ) to produce 2 . $\mathrm{N}$-Benzy lacetanude (3) is subsequently formed by $\mathrm{S}_{\mathrm{N}} \mathrm{l}$ loss of ThO from 2. 


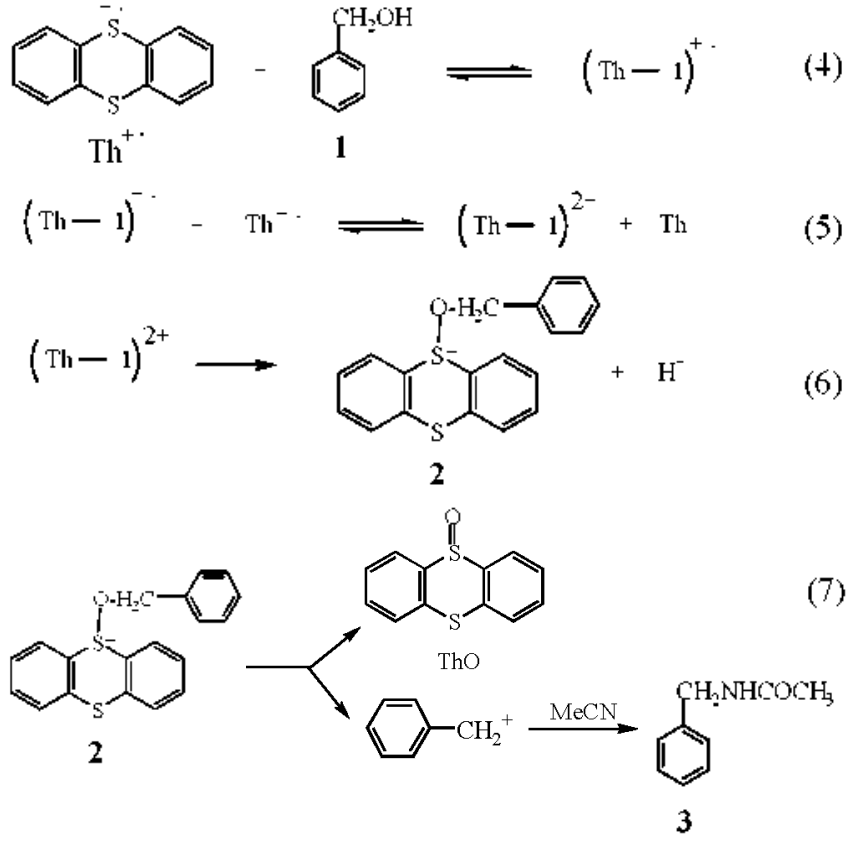

In conclusion a stable benzyl cation was obtained from the complexation of benzy'l alcohol with a thianthrene cation radical under mild conditions. The postulated intermediate. the benzyl cation, has received scant attention because of very few examples of Ritter-type reaction from the cation radical reactions. The new reaction described herein further expands the characteristic benzy' cation chemistry induced by cation radicals.

\section{Experimental Section}

Reaction of benzyl alcohol (1) with $\mathrm{Th}^{+} \mathrm{ClO}_{4}^{-}$, A general procedure was adopted. Solid $\mathrm{Th}^{+} \mathrm{ClO}_{4}{ }^{-}(315.6 \mathrm{mg}$. $1.0 \mathrm{mmol})$ was weighed into a $50-\mathrm{mL}$ rounded-bottomed flask containing a magnetic bar and capped with a septum. The flask was purged with dry argon through a syringe needle, and into it was injected $15 \mathrm{~mL}$ of acetonitrile. The solution was stirred for $10 \mathrm{~min}$. and to it was added. by syringe, a solution of benzyl alcohol ( $54.07 \mathrm{mg} .0 .5 \mathrm{mmol}$ ) in $5 \mathrm{~mL}$ of acetonitrile. The dark purple color of $\mathrm{Th}^{+{ }^{+}} \mathrm{ClO}_{4}{ }^{-}$disappeared within $30 \mathrm{~min}$, but the mixture was stirred overnight. Thereafter, $10 \mathrm{~mL}$ of water was added followed by aqueous $\mathrm{NaHCO}_{3}$ to neutralize $\mathrm{HClO}_{4}$ that had formed during the reaction. The solution was extracted with $3 \times 30 \mathrm{~mL}$ portions of $\mathrm{CH}_{2} \mathrm{Cl}_{2}$. The $\mathrm{CH}_{2} \mathrm{Cl}_{2}$ solution was dried over $\mathrm{MgSO}_{4}$ and evaporated. The residue was dissolved in $10 \mathrm{~mL}$ of $\mathrm{CH}_{2} \mathrm{Cl}_{\text {. }}$. Portions of this solution were used for quantitative analysis by $\mathrm{GC}$ and for identification of products by $\mathrm{GC} / \mathrm{MS}$ and ${ }^{1} \mathrm{H}-\mathrm{NMR}\left(\mathrm{CDCl}_{2}\right)$. The GC column used was a $15 \mathrm{~m} \times 0.25 \mathrm{~mm}$ capillary column with CP-Sil 5CB. with naphthalene as an internal standard. Concentration factors for all products were deternnined with authentic materials.

Thinatherene 5-oxide (ThO) ${ }^{19}$ and $N$-Bemzylacetamide (3) were prepared as described in the literature.

Acknowledgments. We thank the Korea Basic Science Institute. Gwang-Ju center for GC/MS and ${ }^{1} \mathrm{H}-\mathrm{NMR}$.

\section{References and Notes}

1. Hammerich, O.; Parker, V. D. Adv. Phvs. Org. Chem, 1976, 13, $155-278$

2. Shine, H. T:- Yueh, W. Tetrohedron Lett. 1992,33,6583.

3. Shine, H. T: Yueh, W. J. Org. Chemt 1994, 59, 3553.

4. Park, H.-J; Lee, W. K. Bull. Koreon. Chem. Soc. 2005, 26, 1335.

5. Unpublished work, N-benzylacetamide was obtained from the reaction of benzyl phenyl ether and thianthrene cation radical.

6. Shine, H. T. In The Chemismy of the Sulfowim Group; Stirling. C. I. M., Patai, S., Eds.: Wiley: New York, 1981: Chapter 14.

7. Shine, H. I.; Murata, Y.J. Oig. Chem 1969, 34, 3368.

8. Svanholm, U.: Hammerich, O.; Parker, V. D. J. Am. Chem Soc. $1975,97,101$.

9. Shine, H. J.: Silber, I. I:; Bussey, R. H.: Okuyama, T. J. Org. Chem. 1972, 17,2691

10. Chiou, S.; Hoque, A. K. M. M.; Shine, H. I. J. Org. Chent. 1990. 55,327 .

11. Han, D. S.; Shine, H. J. J. Ong. Chent 1996, 61, 3997.

12. Cho, K.-H.; Lee, W. K. Bull Korean Chem. Soc. 2007, 38, 911.

13. Park, Y. S. Lee, W. K. Bull Korean Chent. Soc. 1997, 18, 360.

14. Choi, T. M; Ma, E.-K; Soln, C. K; Lee, W. K. Bull Koneon Chent Soc. 2000, 21, 1254

15. Park. Y. S.; Han, D. S.; Lee, W. K. Bull. Konean Chent. Soc. $1998,19,615$

16. Chung, J. H.; Lim, S. H.: Solu, C. K.; Lee, W. K. Bull Korean Chem. Soc. $1998,19,792$.

17. Park, B. K.: Sohn, C. K.; Lee, W. K. Bull Korean Chem Soc. 2002, 23, 103 .

18. Park, B. K.: Lee, W. K. Bull Korean Chem Soc. 2003, 24, 655.

19.Gilman, H.: Swayampati, D. R. J. Am. Chem. Soc. 1955, 77, 3387

20. Parris, C. L. In Organic Synthesis; Baumgarten, H. E., Ed.; John Wiley: New York, 1973; Coll. Vol. V, p 73. 